\title{
JOURNAL.RU
}

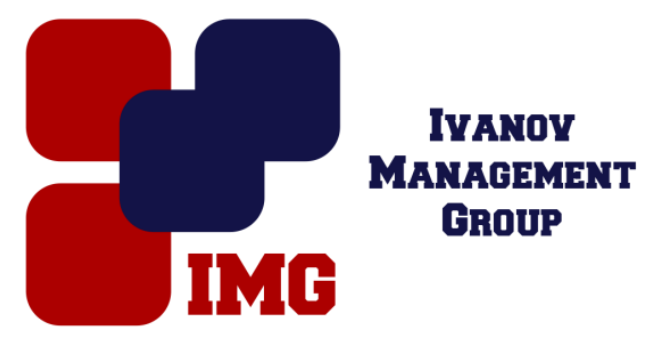

Щербаков Д.В., Степанов А.Н., Токарева Г.М.

Государственное бюджетное учреждение здравоохранения Московской области «Центральная клиническая психиатрическая больница»

Москва, Россия

doi: $10.18411 / 1 \mathrm{j}-30-06-2017-48$

idsp 000001:1j-30-06-2017-48

\section{Клинико-социальные и психопатологические характеристики психически больных с криминальным и нормосообразным поведением}

\section{Аннотация}

В статье представлены результаты сравнительного анализа клинических, социальных и психопатологических характеристик психически больных с криминальным и нормосообразным поведением.В изучаемых группах пациентов обнаружены статистически значимые различия в осознаваемой пациентами негативно-личностной симптоматике, при этом различия по продуктивнопсихотической симптоматике не выявлены.Представленная информация может быть использована в судебно-психиатрической практике при составлении программ психологической реабилитации лиц с психическими расстройствами, совершавшими общественно опасные деяния.

Ключевые слова: психически больные, общественно опасные деяния, характеристики лиц с психическими расстройствами.

\section{Abstract}

Results of the comparative analysis of clinical, social and psychopathological characteristics mentally sick with criminal and holes-mosoobraznym behavior are presented in article. In the studied groups of patients statistically significant distinctions in the negative and personal symptomatology realized by patients are found, at the same time distinctions on productive and psychotic symptomatology are not revealed. The provided information can be used in forensic-psychiatric practice by drawing up 
programs of psychological recovery of persons with the mental frustration making socially dangerous acts.

Keywords: mentally sick, socially dangerous acts, characteristics of persons with mental disturbances.

\section{Введение}

Важным аспектом научного анализа в судебной психиатрии является изучение комплекса факторов, влияющих на формированиепротивоправного поведения лиц, страдающих психическими расстройствами (Дмитриева Т.Б., 2000; Шостакович Б.В., 2001; Казаковцев Б.А., 2001; Мальцева М.М., Котов В.П., 2005; Кондратьев Ф.В., 2006; Усов Г.М., 2008 и др.).

Многие судебные психиатры отмечают высокий риск совершениялицами, имеющими психические расстройства, опасных деяний, нередко связанных с насилием, а такжесообщают о значительных показателях их повторности (Ипатов М.Ю., 2000; Осколкова С.Н., 2005; Кондратьев Ф.В., 2006; Усюкина М.В. 2006; Дмитриева Т.Б. и др., 2009).

Еще в 1994 году Карпов А.С. сообщал о высокой частоте правонарушений, совершаемых психически больными: от $1 \%$ до $20 \%$ по отдельным видам преступлений (Карпов А.С., 1994). В дальнейшем в России одновременно с общим ростом преступности отмечался рост правонарушений среди психически больных (Дмитриева Т.Б. 1997, 2000).

Согласно статистическим данным, в 2005 году на 1000 зарегистрированных психически больных 12,9\% совершили общественно опасные деяния (ООД), в связи с чем были направлены на СПЭ, а в 2015 году этот показатель увеличился и составил 19,8\% случаев (самый высокий показательза последние 10 лет) [5].

На этом фоне сохраняется актуальность совершенствования методов профилактики общественно опасных действий лиц, страдающих психическими расстройствами (Морозов Г.В., Шостакович Б.В., 1987; Мальцева М.М., Котов В.П., 1995; Дмитриева Т.Е., Шостакович Б.В., 1999, 2002; Макушкин Е.В. 2013; Ткаченко А.А. 2013).В связи с этим дальнейшее изучение особенностей пациентов, совершавших и не совершавших правонарушения, является необходимым для выявления характеристик, оказывающих влияние на противоправное поведение [1,2,3,4].

Нами было проведено исследование, целью которого являлось выделениев ходе сравнительного анализа клинических, социально-демографических и психопатологических характеристик, а также субъективных представлений о 
наличии негативно-личностной и продуктивно-психотической симптоматики у лиц с психическими расстройствами, совершавших и не совершавших ООД.

\section{Материал и методы исследования.}

Было обследовано 126 психически больных мужчин в возрасте от 19 до 67 лет, представляющих две группы: первую группу составили 92 пациента, совершавших ООД, вторую группу - 34 пациента, не совершавших правонарушения. В каждой группе 50\% обследованных имели диагноз F20-F21 и 50\% диагноз F06-F07.

В карте обследования пациента фиксировались клинические, социальнодемографические и психопатологические переменные, субъективные представления о наличии негативно-личностной и продуктивно-психотической симптоматики. Использовались данные из медицинской карты амбулаторного больного форма 25/y-04 и медицинской карты стационарного больного форма 003/y. Статистическая обработка материала проводилась с использованием пакета прикладных программ Statistica 20.0. Для оценки достоверности различий в выборках применялся критерий Манна-Уитни, для определения значимых различий в частоте встречаемости явления анализировались таблицы сопряженности.

\section{Анализ результатов исследования.}

Для определения клинических, социально-демографических, психопатологических характеристик лиц, совершавших и не совершавших ООД, был проведен анализ таблиц сопряженности, который показал следующее.

Пациентов, совершивших ООД, по сравнению с пациентами, не совершавшими правонарушения, значимо отличают такие особенности социальных взаимоотношений как конфликтные отношения с отцом в детском возрасте $(\square \square \square 5,705, \mathrm{p}=0,017)$ и частые конфликты со сверстниками $(\square \square \square 8,798$, $\mathrm{p}=0,003)$. Пациенты, совершившие ООД, значимо чаще во время учебы в школе пропускали занятия, имели плохую успеваемость ( $\square \square \square 5,234, \mathrm{p}=0,022)$, школу не окончили $(\square \square \square 3,999, \mathrm{p}=0,046)$. Во взрослом возрасте отмечается проявление агрессии на родственников $(\square \square \square 13,252, \mathrm{p}=0,000)$ или на ближнее окружение $(\square \square \square 4,014, \mathrm{p}=0,045)$.

Психопатологические особенности пациентов, совершивших правонарушения, достоверно чаще проявляются в виде отягощенной алкоголизмом наследственности родственников $(\square \square \square 3,966, \quad \mathrm{p}=0,046)$, нарушением сна в детском возрасте $(\square \square \square 4,454, \mathrm{p}=0,035)$ и наличием диагноза «Синдром гиперактивности с дефицитом внимания» ( $\square \square \square 5,076, \mathrm{p}=0,024)$. Во 
взрослом возрасте - эпизодической алкоголизацией ( $\square \square \square 4,441, \mathrm{p}=0,035)$, злоупотреблением алкоголем ( $\square \square \square 7,665, \mathrm{p}=0,006)$, наличием инвалидности по психическому заболеванию $(\square \square \square 4,640, \mathrm{p}=0,031)$.

Лица, совершившие правонарушения, по сравнению с лицами, не совершавшими ООД, значимо чаще имеют две и более госпитализаций в психиатрический стационар ( $\square \square \square 6,247, \mathrm{p}=0,012$ ), принимают психотропные препараты ( $\square \square \square 3,962, \mathrm{p}=0,047)$. Для них чаще характерен быстропрогредиентный характер течения заболевания с частыми обострениями $(\square \square \square 3,797, \mathrm{p}=0,051)$.

В группе лиц, не совершавших ООД, по сравнению с лицами, совершившими правонарушения, значимо больше лиц, имевших среднюю успеваемость в школе $(\square \square \square 12,519, \mathrm{p}=0,000)$, работающих в коммерческих структурах $(\square \square \square 12,799, \quad \mathrm{p}=0,000), \quad$ сферах здравоохранения, культуры и образования ( $\square \square \square 10,111, \mathrm{p}=0,001)$ по высококвалифицированным профессиям ( $\square \square \square 4,308, \mathrm{p}=0,038)$.

Социальные взаимоотношения лиц, не совершавших ООД, значимо чаще характеризуются тесными, эмоционально теплыми отношениями в детстве с отцом $(\square \square \square 6,898, \mathrm{p}=0,009)$, во взрослом возрасте отсутствием в их поведении агрессии по отношению к окружающим ( $\square \square \square 28,379, \mathrm{p}=0,000)$, частым общением с родственниками при хороших отношениях с ними $(\square \square \square 9,858, \mathrm{p}=0,002)$.

В группе пациентов, не совершавших ООД, значимо больше лиц, которые не проходят лечение у врача психиатра и не получают психотерапевтическое лечение $(\square \square \square 14,859, \mathrm{p}=0,000)$, один раз госпитализировались в психиатрический стационар ( $\square \square \square 18,173, \mathrm{p}=0,000)$.

С целью сравнения данных, полученных при изучении субъективных представлений о наличии негативно-личностной и продуктивно-психотической симптоматики у лиц, совершавших ООД и не совершавших правонарушения, был проведен частотный анализ.

В результате проведения дескриптивного анализавсего массива полученных данных выявляется, что большинство пациентов, совершивших правонарушения, считают себя малоэмоциональными (60\%) и не обидчивыми (61\%), в то же время, среди пациентов, не совершавших правонарушения, выделяют у себя данные характеристики $38 \%$ и $47 \%$ обследованных, соответственно.

Полагают, что они несклонны делиться своими переживаниями, 70\% лиц с криминальным анамнезом и 46\% лиц без криминального анамнеза. Из числа обследованных, совершивших правонарушения, 33\% отмечают, что с трудом собираются с силами, чтобы начать что-то делать, в то же время из пациентов, не 
совершавших ООД, на наличие у них данных особенностей указывают 53\% обследованных, соответственно.

О периодических ощущениях печали, уныния и беспомощности заявляют $50 \%$ лиц, совершавших ООД, и $32 \%$ лиц, не совершавших правонарушения. Приступы сильного страха отмечают 32\% лиц с криминальным анамнезом и 20\% без криминального анамнеза.

Оценивая особенности социальных взаимоотношений, полагают, что окружающие относятся к ним враждебно и недоброжелательно $21 \%$ пациентов, совершавших ООД, и 15\% пациентов, не совершавших правонарушения.

Заявляют о наличии у них нарушений внимания в виде повышенной отвлекаемости 53\% лиц, совершивших ООД, и 33\% лиц, не совершавших правонарушения, о невнимательности по отношению к окружающим - $44 \%$ и $32 \%$ пациентов, соответственно. При этом, 34\% представителей первой группы отмечают у себя снижение реакции на окружающих, даже на громкие звуки, но только $12 \%$ обследованных, относящихся ко второй группе, сообщают о наличии у себя данных проявлений.

Заявляют о том, что способны воспринимать то, чего не видят и не слышат другие люди, 28\% пациентов, совершавших ООД, и 18\% не совершавших ООД. О наличии навязчивых и фантастических мыслей, которые кажутся нереальными, сообщают, соответственно, 65\% и $38 \%$ пациентов, совершавших ООД, а также $54 \%$ и $26 \%$ пациентов, не совершавших правонарушения.

При сравнении полученных описательных статистик и выделении значимо отличающих группы характеристик использовался критерий U-Mann-Whitney. B изучаемых группах пациентов обнаружены статистически значимые различия восознаваемой пациентами негативно-личностнойсимптоматике. Различия по продуктивно-психотической симптоматике не выявлены.

\section{Заключение}

Таким образом, проведение сравнительного анализа полученных данных позволило выявить статистически значимые различия в клинических, социальных и патопсихологических характеристиках, а также субъективных представлениях о наличии негативно-личностной и продуктивно-психотической симптоматики упсихически больныхс криминальным и нормосообразным поведением.

Пациентов, совершавших ООД, значимо отличают от лиц, не совершавших правонарушения, проявления социальной дезадаптации, начиная с детского возраста, в виде конфликтных отношений с отцом и частых конфликтов со 
сверстниками. Во взрослом возрасте - в виде проявления агрессии на родственников или на ближнее окружение.

Для них характерны большое количество экзогений, синдром гиперактивности с дефицитом внимания в детстве, а во взрослом возрасте эпизодическая алкоголизация или злоупотребление алкоголем.

У лиц, совершавших ООД, достоверно чаще отсутствует динамика течения психического заболевания, для них характерны частые обострения психического заболевания и резистентность к психотерапевтическим воздействиям, несмотря на частую госпитализацию в психиатрическую больницу. Они чаще являются инвалидами по психическому заболеванию, отличаются неадекватно-позитивным восприятием субъективного качества жизни.

В отличии от лиц, совершавших правонарушения, в группе пациентов, не совершавших ООД, значимо больше лиц, имеющих более высокий трудовой статус, уровень академической успеваемости и социальной адаптации. Они реже обращаются к врачу-психиатру, имеют минимальное количество госпитализаций в психиатрической стационар.

Пациенты, совершавшие ООД, чаще, чем пациенты, не совершавшие правонарушения, отмечают у себя следующие негативно-личностные проявления: снижение эмоциональности, нарушение абстрактного мышления, эмоциональную отгороженность.

Пациенты без криминального анамнеза чаще, чем пациенты, совершавшие правонарушения, сообщают о повышенной отвлекаемости и пассивноапатической социальной отгороженности (ощущение печали, уныния и беспомощности, необходимость собраться с силами, чтобы приступить к деятельности). 
1. Булыгина В.Г. Психологическая концепция профилактики общественно опасных действий лиц с тяжелыми психическими расстройствами: Автореф. дис... д-ра. мед. наук. - М., 2015. - C.4-5.

2. Казаковцев Б.А., Малкин Д.А., Букреев Н.В., Булыгина В.Г. Совершенствование деятельности психиатрических больниц специализированного типа с интенсивным наблюдением // Психическое здоровье. - 2011. - № 5. - С. 3-31.

3. Котов В.П., Шишков С.Н., Полубинская С.В. и др. Современное состояние законодательного регулирования порядка исполнения предусмотренных уголовным кодексом принудительных мер медицинского характера в отношении лиц с тяжелыми психическими расстройствами // Психическое здоровье. - 2013. - Т. 11. № 7 (86). - C. 3-15.

4. Макушкина О.А., Голланд В.Б., Яхимович Л.А. Значение мер медицинского характера в системе профилактики общественно опасных действий психически больных // Российский психиатрический журнал. - 2013. - № 4. - С. 20-26.

5. Мохонько А.Р., Макушкин Е.В., Муганцева Л.А. Основные показатели деятельности судебно-психиатрической экспертной службы Российской Федерации в 2015 году: Аналитический обзор. - М., 2016. - С. 17. 